\title{
Improving the Eighth Graders’ Motivation Toward Science Learning Through Inquiry-Based Teaching
}

\author{
Jeng-Fung Hung, Men-An Pan, Kun Lee \\ National Kaohsiung Normal University, Kaohsiung, Taiwan
}

\begin{abstract}
This study aimed to improve the eighth graders' motivation toward science learning through inquiry-based teaching and provide various evidences through cross-comparisons regarding the students' classroom environment perceptions. The quasi-experiment design was adopted for this study with the subjects being the eighth graders from four classes of a junior high school in Kaohsiung City, Taiwan. Two of the classes were assigned to the experiment group (74 students) and the other two were the control group (75 students). The inquiry-based teaching was applied to the experiment group while the traditional textbook teaching with cookbook experiments was applied to the control group. The teaching duration was the first semester for the eighth graders with a total of six learning units being taught in this period of time. The multi-variate analysis of variance (MANOVA) was applied with the dependent variables being motivation toward science learning and classroom environment perception and alpha being set to 0.05 . It was found that the students in the experiment group were more likely to perceive the supportive inquiry-learning environment. And two of their intrinsic motivations-science learning value and learning environment stimulation, were stronger than the students in the control group. However, the extrinsic motivation-performance goal, of the students in the control group was stronger.
\end{abstract}

Keywords: classroom environment perception, inquiry-based learning environment, science learning motivation

\section{Introduction}

Many teenage students do not have any motivation to learn science. They find science difficult and annoying as a subject (Rennie, Goodrum, \& Hackling, 2001). Motivation is a key factor behind learning. It is an internal process of initiating, guiding, and sustaining for a period of time hard-working behaviors (Pintrich, 2003; Stipek, 2002). Not having any motivation to learn science means the possibility of meaningful learning is reduced.

Motivation is not a single-dimensional construct. Understanding the types of motivations is essential to facilitate learning. The characteristics and thinking patterns of students with learning motivations are as below:

1. They have high self-efficacy and believe in the influences of their own efforts and abilities on learning progress. As a result, they would work harder and be more persistent (Bandura, 1997; Zimmerman, 1998);

Jeng-Fung Hung, Ph.D., professor, Graduate Institute of Science Education and Environmental Education, National Kaohsiung Normal University.

Men-An Pan, Ph.D. student, Graduate Institute of Science Education and Environmental Education, National Kaohsiung Normal University.

Kun Lee, Ph.D. student, Graduate Institute of Science Education and Environmental Education, National Kaohsiung Normal University. 
2. They have learning goals, so they would look for useful information and come up with strategies in order to obtain, develop, and improve knowledge and skills for themselves (Butler, 2000; Vermetten, Lodewijks, \& Vermunt, 2001);

3. They have so-called optimistic attributional style. It means that when facing frustrations in learning or performing, they believe they can put in more efforts and apply more strategies to change the cause of the frustrations (Schunk, 2000);

4. They have intrinsic motivations, so they would put in efforts to achieve their learning goals and meet and overcome them on their own initiative (Ryan \& Deci, 2000);

5. Their self-regulation is efficient. They would set up goals, apply effective strategies, monitor the cognitive process, review feedbacks, and make adjustments when necessary (Zimmerman, 2002).

\section{Literature Review}

In order to increase students' learning motivations, it is essential to support conditions from their learning environment by the followings:

1. Helping them to further understand the course value through explaining why it is worthy to work hard for the course, so that their motivations can be sparked (Reeve, Jang, Hardre, \& Omura, 2002);

2. Arousing their curiosity as they would be inspired to put efforts in exploring if they are aware of their knowledge gap (Loewenstein, 1994);

3. Developing their situational interest by exciting their interest though events or experiences in the classroom that are autonomous (offering them an opportunity to make meaningful choices), novel, surprising, with suspension, and debatable as this short-period interest is a trigger for students to spontaneously get involved in the activity (Anderman, Noar, Zimmerman, \& Donohew, 2004; Schraw, Flowerday, \& Lehman, 2001; Palmer, 2009);

4. Advancing their goals through seeing their progress as a kind of success, their efforts as valuable and their mistakes an essential part of learning and focusing on their learning process, so that they would believe the purpose of participating in school activities is to learn instead of to get good grades (Anderman et al., 2001);

5. Conducting an instructional conversation in the situation arranged with group discussions to help them think about the topic of the conversation, so that they can learn to work with a group and learn a lot more through presentations, communications, arguments, and convincing other students (Rogoff, Turkanis, \& Bartlett, 2002);

6. Increasing collective efficacy, which is a common belief of individuals who participate in a valuable activity together that their fighting strength would be higher when working as a team (Bandura, 2000).

In a science classroom, the best way to support students' curiosity, exploration, and desire for knowledge is to start with an open inquiry and encouraging them to associate with their previous knowledge and imagination to come up with various ideas, create hypotheses, identify independent variables, and arrange control variables (Starko, 2005). Teachers would find that using this method can increase their students' interest, so that their students would be inspired to explore. Because the inquiry is open, there can be diversified answers, which are based on the exercises, trials-and-errors, interactions, and conversations with ideas and concepts. The characteristics of this classroom inquiry-based teaching include the followings: 
1. Students have different viewpoints on the same event they observe and are curious about why;

2. Teachers see "wrong responses" as successful results, so the misconceptions can be resolved;

3. Students can experience successes through looking for answers to scientific puzzles and predicting results;

4. Students learn to face mistakes with a positive attitude and try to discover why they make mistakes;

5. Students can develop better comprehensive capability by verifying their findings;

6. Students may continue to explore the environment around them with inquiry-based learning (Oliver, 2006).

The first characteristic is about creating knowledge gaps to raise curiosity, the second to fifth characteristics are about advancing their learning-oriented goals, and the sixth characteristic is about raising curiosity to go into whys and wherefores.

A study by Wang and Lin (2009) found that junior high school students and elementary school students in Taiwan have very few chances to engage in inquiry activities. Once in a while, after teaching, teachers would instruct their students to perform experiments on their own. However, students can hardly express their thoughts. In the experimental activities of the textbook, the students follow the experimental activities provided by the textbook without the need for thinking. They do the activities step by step to avoid failure and verify the contents of the textbook. Although these are hands-on learning activities, there is no space for independent thinking, not to mention intellectual participation and challenges. In this kind of processes, students do not need to actually think. As a result, they are not curious about exploring things, the space for imagination is limited, and the excitement of finding answers through science is reduced (Bell, Blair, Crawford, \& Lederman, 2003; Chinn \& Malhotra, 2002; Hickey, Kindfield, Horwitz, \& Christie, 2003).

Based on the literature review above, increasing students' motivations to learn science requires not only conditions, which support learning motivations, but also an inquiry-based learning environment. In view of this, this study aimed to design inquiry-based teaching according to the conditions of supporting learning motivations, for improving the eighth graders' motivations to learn science.

\section{Research Design}

The quasi-experiment design was adopted for this study. In the aspect of teaching treatments, the inquiry-based teaching was applied to the experiment group while the traditional textbook teaching with cookbook experiments was applied to the control group. The research subjects were eighth graders. And the duration of the teaching treatments was the three and a half months of the first semester. In the last week of the semester, the students of both groups had to take the post-test by with the "What is happening in this class? (WIHIC) scale” and the "students' motivation toward science learning (SMTSL) scale.” There was no pre-test for covariates. The reason was that the teaching treatments were applied in the science course in the first semester for the eighth graders with the content of science of matter while the content taught in the science course for seventh graders was biology-related. Not only had the attributes of the course, but also the teachers of the course changed when the students went into the Grade 8. Under this circumstance, conducting a pre-test for science classroom environment perception and science learning motivation scale and using the scores as covariates was not appropriate. 


\section{Subjects}

The subjects of the experiment group and the control group were the eighth graders from four classes of a junior high school in Kaohsiung City, Taiwan. The school was a large school with 20 Grade 8 classes. In addition, the grouping method used by the school was normal class grouping. There were 74 students in the experiment group and 75 in the control group. The two classes of the experiment group were taught by the same teacher, while the two classes of the control group were taught by two teachers respectively with similar seniority and academic backgrounds as the teacher for the experiment group.

\section{Treatment}

\section{Overview}

The teaching materials used in this study were the six learning units of the science course for eighth graders. For both the experiment group and the control group, the learning activities were conducted by groups with about five students in each group. Because the numbers of lessons for the learning units for the experiment group were all higher than the control group by one lesson, in order to make sure the teaching hours for the two groups were the same, one extra lesson to do the exercises in the textbook was included for each learning unit for the control group.

The teaching activities for the control group were based on the contents of the textbook. Firstly, the teachers taught the students the science theories and knowledge, and then, they explained the purposes, equipments, steps, and results of the experiment to be performed. After that, the students followed the instructions in the textbook to perform the experiment. When the experiment was done, the data and analysis results were recorded in the experiment log. Students answered the questions raised by the textbook, and then, the teacher scores the student's answer. This kind of experiments is called cookbook experiments.

The inquiry-based teaching method for the experiment group was designed based on the conditions to stimulate learning motivations in the literature review. The purpose was to build a supportive learning environment where the students could feel being respected and accepted. In this environment, the teacher turned the students' observations into questions and performed inquiry activities based on these questions, to ignite their passion for learning, encourage them to explore as a team, and give them time to think about and discuss their findings. These inquiry-based learning activities for igniting learning motivations left the students more time to explore and discover the patterns and relationships in scientific phenomena instead of verifying the patterns and relationships specified in the textbook. These activities are to construct and develop evidence-based explanations instead of merely listening to their teacher's explanations and to communicate and debate on their arguments instead of simply coming up with a correct answer. The steps of the inquiry-based teaching activities based on the principles above are summarized as below:

1. Dividing the students into groups for the experiment activities with open conditions;

2. Showing different observations of the same event through the groups' presentations to arouse the students' curiosity, so that they would ask questions to find out why;

3. Encouraging the students to associate their knowledge to summarize their designs of experiments and findings, to discuss with their group members, and to find out possible reasons;

4. Through the class presentations, once again summarizing the presentation contents of the groups in order to confirm possible reasons; 
5. Selecting one possible reason for exploration with the process, including design of experiments, data collection and analyses, and proposing possible patterns;

6. Through the class presentations, exchanging designs of experiments, experiment results, and patterns found among groups and allowing the students to defend their experiment results;

7. Through group discussions, summarizing the group findings to confirm the patterns found;

8. Reflecting the differences in viewpoints before and after the exchange and the reasons behind the viewpoint changes;

9. The teacher's clarification and guidance to integrate the students' findings into scientific laws;

10. Reviewing the students' exploration and learning to enhance their comprehension and inquiry-based capabilities.

The structures of the six learning units for the experiment group were all suitable for the steps of the inquiry-based teaching activities. The questions listed in Table 1 were used as the frame for inquiry-based learning in order to provide the students hints and supports. The frame in Table 1 contains three parts based on the three elements of inquiry, namely, exploration, explanation, and communication. The teacher could use different questions based on the actual learning conditions of the students.

Table 1

The Question Frame for Supportive Inquiry-Based Learning

\begin{tabular}{|c|c|}
\hline \multicolumn{2}{|c|}{ Timing for the teacher question to be asked to ask question } \\
\hline Exploration & $\begin{array}{l}\text { How do you design a research question? } \\
\text { How do you present the data changes through graphs? } \\
\text { When performing the research, which variables will you change, measure, or maintain? } \\
\text { Which data are useful? } \\
\text { What are the patterns in the data? } \\
\text { Can these patterns be used for this inquiry? }\end{array}$ \\
\hline Explanation & $\begin{array}{l}\text { How do you explain this pattern? } \\
\text { Can you come up with other reasonable explanations based on the related evidences? } \\
\text { Can the evidences support your explanation? } \\
\text { After referring to the evidences, how do you modify your idea? } \\
\text { Is this explanation sufficient to answer the question asked? }\end{array}$ \\
\hline Communication & $\begin{array}{l}\text { How do you convince your classmates what your finding is important and valid? } \\
\text { How do you defend your own explanation? } \\
\text { Do others do well in the research with their control variables? } \\
\text { Is there any evidence to support others' explanations? } \\
\text { What is the influence of others' conclusions on your idea? } \\
\text { Would you change your idea after comparing your conclusion with others? Why or why not? }\end{array}$ \\
\hline
\end{tabular}

\section{The Activities}

Below is an example with the fourth learning unit "Heat and water temperature changes" for the purpose of elaboration with the corresponding conditions to inspire learning motivations enclosed in parentheses in bold.

Activity 1. At the beginning, an open situation scenario was provided. The students were asked to heat water for two minutes. They could decide which beaker to use, how much water to heat, and the flame size on their own (developing situational interest). Then, the students were asked what data they wanted to record for this kind of activity. In this inquiry-based activity, the teacher could see if the students included independent variables and dependent variables in their data and if they recorded some data as control variables. This part is the first step of inquiry-based teaching activities listed above. 
Activity 2. After the students completed Activity 1, each group wrote down their design of experiments and measured water temperature changes on the whiteboard and presented their results to the class for the purpose of group communications and exchanges based on the comparisons of the results with other groups (instructional conversation). In Activity 1 , all conditions could be determined by the students except for the heating time of two minutes. Thus, the water temperatures obtained by the groups after heating the water would be different. The purpose was to arouse their curiosity to find out why and increase their learning motivations (arousing curiosity), so that they would think about the factors influencing the water temperature changes and reflect on the control variables they had to take into consideration in order to study these factors (further understanding of experiment goals and values). During the group presentations, the teacher asked the presenting group to bring their whiteboard to the front of the classroom for other students to see. Moreover, the teacher asked the presenter to face the class instead of facing the whiteboard and reading out what was written on it. This helped the students to learn to do presentations and communicate with others. After a group's presentation was done, the students of other groups asked questions about the contents of the presentation. And the students of the presenting group could explain or defend their theories (developing situational interest). This part is the second step of inquiry-based teaching activities listed above.

Activity 3. After all the groups finished their presentations, the students were asked to perform group discussions first. Through these discussions, they could think about other groups' presentations and reach common consensus about possible factors behind the water temperature changes. Then, each group had to do a second presentation. After the communications and exchanges, group discussions were performed again to compare the possible factors behind the water temperature changes they proposed with those other groups proposed to come up with the final consensus (increasing collective efficacy). All the factors influencing the water temperatures were listed and ordered based on their importance. The purpose was to allow the students to practice critical thinking and to prepare for the next activity. This part is the third and fourth steps of inquiry-based teaching activities listed above.

Activity 4. The groups were asked to pick one factors that they wanted to study among all the factors influencing water temperature changes, namely, mass of water, container material, container size, flame size, distance between container and flame, heat source, and whether there was wind (developing situational interest). To avoid the situation where all the groups picked the simplest factor to design their experiments, the teacher could apply some techniques to make sure that each factor was selected by a group. In Activity 4, the students had to describe specifically the variable they wanted to study and the corresponding hypothesis and design of experiments. Based on these, they began their inquiry-based activity by collecting data, analyzing data, discovering patterns based on their findings, and coming up with a conclusion. The teacher could use this chance for education, by reminding the students the importance of control variables in design of experiments (advancing learning goals). The purpose of this activity was for the students to inquire. For the experiments they designed, the students could discover different patterns through charting their data. This activity involved the students' creative thinking and critical thinking (further understanding of experiment goals and values). This part is the fifth step of inquiry-based teaching activities listed above.

Activity 5. After the group inquiry was completed, the students wrote down their results on the whiteboards for the third class presentations and communications. The purpose of this process was to facilitate communications and exchanges among the students regarding their designs of experiments and findings in relations to patterns and to give them a chance to defend their own ideas and experiment results by convincing 
other students while learning from other groups (conducting instructional conversation). Here, the students' critical thinking was involved. After the presentations, the whiteboards were placed on the stage in front of the classroom for the students to compare how other groups present their data in order to learn from each other (increasing collective efficacy). After the third presentations and communications, group discussions were performed again for the students to confirm the main factor behind the water temperature changes and to review their thoughts before and after the communications and the reasons for that (advancing learning goals). After Activity 5 was completed, the students still could not discover the law of heat change (heat absorbed by water $=$ constant $X$ mass of water $X$ temperature difference). The reason was the students did not have sufficient science knowledge. They could only discover some patterns in the inquiry-based activity. It required the teacher's guidance to associate their findings to the scientific law. This part is the sixth, seventh, eighth, and ninth steps of inquiry-based teaching activities listed above.

Activity 6. After the inquiry-based activity, presentations, and communications, lastly, the students were asked to review their inquiry process to think about what issues they could further study. The purpose of this activity was to facilitate the students' introspections for this process and practice of meta-cognitive thinking (further understanding of experiment goals and values). This activity could be left as the afterschool assignment for the students. This part is the 10th step of inquiry-based teaching activities listed above.

In the inquiry-based teaching activity described above, the teacher would ask questions from Table 1 when necessary based on the students' learning conditions and needs, to help them think and learn while inquiring.

\section{Instrument}

\section{WIHIC Scale}

The students' perception of the science classroom environment was measured using the WIHIC scale, which was developed by Fraser, McRobbie, and Fisher (1996) and revised by Huang, Fraser, and Aldridge (1998) with seven dimensions:

1. Student cohesiveness: Students getting to know each other, helping each other, and supporting each other;

2. Teacher support: Including teacher's assistance, friendliness, trust, and interest in his/her students;

3. Involvement: Students being interested in participation, discussions, and extra learning and being happy to attend class;

4. Investigation: Focusing on investigation skills and processes and applying them to problem solving;

5. Task orientation: Students caring about completing expected activities and focusing on schoolwork;

6. Cooperation: Students cooperating instead of competing with each other in learning;

7. Equity: Teacher treating his/her students equally.

There were 565 -point Likert items in this questionnaire with the score range being 56-280 points. The subjects were the seventh and eighth graders $(N=1,879)$. The Cronbach $\alpha$ of the scale was 0.95 and those of the subscales were between 0.90 and 0.96 with the discriminant validity values between 0.41 and 0.58 . The factor analysis related values were all desired values. In this study, the Cronbach $\alpha$ of the scale was 0.96 and those of the subscales were between 0.86 and 0.92 .

\section{SMTSL Scale}

The students' motivation toward science learning was measured using the SMTSL scale developed by Tuan, Chin, and Shieh (2005), including six dimensions as below: 
1. Self-efficacy: Students believe in their own ability to perform well in science;

2. Active learning strategies: Students take an active role in using a variety of strategies based on their previous understanding to construct new knowledge;

3. Science learning values: The values of science learning include helping students acquire problem-solving competency, experiencing inquiry activities, stimulating their own thinking, and finding associations of science with things in their daily life. If they can perceive these important values, they would be motivated to learn science;

4. Performance goal: Student's goal in science learning is to compete with other students and get their teachers' attention;

5. Achievement goal: Students feel satisfied as their competences are improved and achievements are extended during science learning;

6. Learning environment stimulation: In a class, the learning environment surrounding, such as curriculum, teachers' teaching, and students' interactions, would influence their motivation toward science learning.

There were 35 5-point Likert items in this questionnaire with the score range being 35-175 points. The subjects were the seventh, eighth, and ninth graders $(N=1,407)$. The Cronbach $\alpha$ of the scale was 0.89 and those of the subscales were between 0.70 and 0.89 . The factor analysis related values were all desired values. In this study, the Cronbach $\alpha$ of the scale was 0.90 and those of the subscales were between 0.77 and 0.86 .

\section{Data Collection and Analyses}

Because both perception of the classroom environment and motivation were multi-dimensional concepts, and some types of motivation were more beneficial for facilitating quality learning. Thus, studying the differences in these dimensions of perception of the science classroom environment and motivation toward science learning between the experiment group and the control group were more important than comparing the total scores of WIHIC and SMTSL. Based on this idea, this study performed multi-variate analysis of variance (MANOVA) with teaching treatment as the independent variable and students' perception of the science classroom environment and motivation toward science learning as dependent variables. The $\alpha$ was set to 0.05 and the effect sizes were determined by $\eta^{2}$. The effect sizes were small, medium, and large with the $\eta^{2}$-value of 0.01, 0.06, and 0.14, respectively (Cohen, 1988; 1992).

\section{Findings and Discussions}

\section{The Perception of the Science Classroom Environment of the Experiment Group and the Control Group}

According to the means and standard deviations of the WIHIC scores and the MANOVA results of the experiment group and the control group in Table 2, the overall Wilk's $\lambda$ was 0.80 , which was significant with alpha being 0.05 . The overall effect size was large with the $\eta^{2}$-value of 0.20 . The further analysis of variance (ANOVA) results showed that except for "student cohesiveness" $(F=2.12, p>0.05)$, the differences in all the other dimensions were significant $(F=7.77-33.14, p<0.05)$. The experiment group's average scores were higher than the control group's scores. The effect size of "investigation" was large $\left(\eta^{2}=0.19\right)$, those of "teacher support" and "involvement” were nearly large $\left(\eta^{2}=0.10\right.$ and 0.12 , respectively) and those of "task orientation," “cooperation," and "equity” were medium $\left(\eta^{2}=0.05,0.05\right.$, and 0.06 , respectively), as shown in Table 2.

According to the results of the perception of the science classroom environment above, the experiment group scored higher in the "investigation" dimension than the control group, meaning that the students of the 
experiment group were more likely to perceive "applying investigation skills and processes to problem solving" in the science classroom environment. This kind of science classroom environment was indeed different from the learning environment using traditional textbook teaching with cookbook experiments. The experiment group scored higher in the "involvement" and "task orientation" dimensions, meaning the students of the experiment group were more likely "to be interested in participation in learning activities and discussions" and "care about completing expected activities and focusing on schoolwork." These results supported the hypothesis that the inquiry-based teaching method used in this study was helpful to increase the SMTSL, especially their intrinsic motivation. The later comparison between the experiment group and the control group regarding their motivation toward science learning can be used as a contrast for this part.

Table 2

MANOVA Results of the WIHIC Scores of the Two Groups

\begin{tabular}{|c|c|c|c|c|c|c|c|c|}
\hline \multirow[t]{2}{*}{ Item } & \multicolumn{2}{|c|}{$\begin{array}{c}\text { Experiment group } \\
(N=74) \\
\end{array}$} & \multicolumn{2}{|c|}{$\begin{array}{c}\text { Control group } \\
(N=75)\end{array}$} & \multirow[t]{2}{*}{ Multi-variateWilk’s $\lambda$} & \multirow{2}{*}{$\begin{array}{l}\text { Multi-variate } \\
F\end{array}$} & \multirow{2}{*}{$\begin{array}{l}\text { Single-variate } \\
F\end{array}$} & \multirow{2}{*}{$\begin{array}{l}\text { Effect size } \\
\eta^{2}\end{array}$} \\
\hline & $M$ & $S D$ & $M$ & $S D$ & & & & \\
\hline MANOVA & & & & & 0.80 & $4.84^{*}$ & & 0.20 \\
\hline Student cohesiveness & 29.00 & 5.79 & 27.47 & 6.87 & & & 2.12 & 0.01 \\
\hline Teacher support & 24.95 & 7.02 & 20.60 & 6.38 & & & $15.32^{*}$ & 0.10 \\
\hline Involvement & 24.42 & 5.80 & 20.28 & 5.79 & & & $18.63^{*}$ & 0.12 \\
\hline Investigation & 23.97 & 6.58 & 17.46 & 7.10 & & & $33.14^{*}$ & 0.19 \\
\hline Task orientation & 27.39 & 6.26 & 24.40 & 6.69 & & & $7.77^{*}$ & 0.05 \\
\hline Cooperation & 28.81 & 6.84 & 25.33 & 7.97 & & & $8.02^{*}$ & 0.05 \\
\hline Equity & 28.49 & 7.36 & 24.58 & 8.58 & & & $8.72^{*}$ & 0.06 \\
\hline
\end{tabular}

Note. ${ }^{*} p<0.05$.

Moreover, the comparison of the "cooperation" dimension showed that the students of the experiment group were more likely to "cooperate instead of compete with each other in learning" than the control group, meaning that the inquiry-based learning environment in this study could facilitate the students to investigate and to cooperate in learning. In addition, regarding the "teacher support" and "equity" dimensions, the students of the experiment group were more likely to perceive "the teacher's assistance, friendliness, and trust" and "the teacher treating the students equally." It means that the students of the experiment group were more likely "to perceive a science classroom environment that could support inquiry-based learning" and "to perceive their teacher's general support for them." However, the difference in "student cohesiveness" between the experiment group and the control group was not statistically significant. One possible reason was that the eighth graders were well acquainted with their classmates. Thus, in-group experiments, the difference in assistance and support for each other between the two groups was not obvious.

Based on the literature review above, this study built a supportive learning environment where the students would find passion for learning and have time for investigation, thinking, and discussions. As a result, compared to the control group, the students of the experiment group were more likely to perceive a supportive classroom environment for inquiry-based learning and their teacher's general support. Because the sequence of the inquiry-based teaching in this study began with encouraging the students to come up with different views on the same thing and be curious about why, as a result, the students from the experiment group had stronger intrinsic motivation toward science learning than the control group. The inquiry-base teaching used in this study was based on Zimmerman's (2004) argument. The students were arranged to participate in discussions, 
compare different ideas, make predictions, design experiments, look for patterns, and learn from each other. As a result, compared to the control group, the students of the experiment group were more likely to complete expected experiment activities and focus on experiments. Moreover, compared to the traditional textbook teaching with cookbook experiments, the sequence of the inquiry-based teaching design which supported the students to work as a team for investigation was more likely to encourage the students to cooperate in learning.

The large to medium effect sizes of the WIHIC dimensions above (except for "student cohesiveness") proved that the influence of the inquiry-based teaching applied by this study on the students' perception was consistent with what the literature described. Thus, this study continued to explore the effects of this inquiry-based teaching on increasing the SMTSL.

\section{The Performances of the Experiment Group and the Control Group in Motivation Toward Science Learning}

According to the means and standard deviations of the SMTSL scores and the MANOVA results of the experiment group and the control group in Table 3 , the overall Wilk's $\lambda$ was 0.85 , which was significant with alpha being 0.05 . The overall effect size was large with the $\eta^{2}$ value of 0.15 . The further ANOVA results showed that only the differences in "science learning value," "learning environment stimulation," and "performance goal” were significant $(F=7.50-17.42, p<0.05)$. And the experiment group's average scores of "science learning value" and "learning environment stimulation" were higher than the control group's scores with medium effect sizes ( $\eta^{2}=0.05$ and 0.07 , respectively). The control group's average score of "performance goal” were higher than the experiment group's score, with a nearly large effect size $\left(\eta^{2}=0.11\right)$.

Table 3

MANOVA Results of the SMTSL Scores of the Two Groups

\begin{tabular}{|c|c|c|c|c|c|c|c|c|}
\hline \multirow[t]{2}{*}{ Item } & \multicolumn{2}{|c|}{$\begin{array}{c}\text { Experiment } \\
\text { group }(N=74)\end{array}$} & \multicolumn{2}{|c|}{$\begin{array}{c}\text { Control group } \\
(N=75)\end{array}$} & \multirow[t]{2}{*}{ Multi-variate Wilk’s $\lambda$} & \multirow{2}{*}{$\begin{array}{l}\text { Multi-variate } \\
F\end{array}$} & \multirow{2}{*}{$\begin{array}{l}\text { Single-variate } \\
F\end{array}$} & \multirow{2}{*}{$\begin{array}{l}\text { Effect size } \\
\eta^{2}\end{array}$} \\
\hline & $M$ & $S D$ & $M$ & $S D$ & & & & \\
\hline MANOVA & & & & & 0.85 & $4.29^{*}$ & & 0.15 \\
\hline Self-efficacy & 20.70 & 3.76 & 20.81 & 4.48 & & & 0.27 & 0.00 \\
\hline Active learning strategies & 28.05 & 5.02 & 27.15 & 5.15 & & & 1.19 & 0.01 \\
\hline Science learning values & 18.09 & 2.94 & 16.56 & 3.84 & & & $7.50^{*}$ & 0.05 \\
\hline Performance goal & 11.93 & 3.33 & 14.11 & 3.03 & & & $17.42^{*}$ & 0.11 \\
\hline Achievement goal & 18.05 & 3.46 & 17.39 & 3.59 & & & 1.33 & 0.01 \\
\hline $\begin{array}{l}\text { Learning environment } \\
\text { stimulation }\end{array}$ & 20.58 & 3.96 & 18.24 & 4.85 & & & $10.40^{*}$ & 0.07 \\
\hline
\end{tabular}

Note. ${ }^{*} p<0.05$.

The two groups were compared regarding their motivation toward science learning. The students of the experiment group scored higher in "learning environment stimulation" than the control group, meaning that the inquiry-based teaching used in this study helped to build "a learning environment surrounding the students with curriculum, teachers' teaching, and students' interactions” to increase their motivation toward science learning. After comparing this finding with the WIHIC analysis results above, it was confirmed that the inquiry-based teaching used in this study could definitely stimulate the students to learn science. The students of the experiment group scored higher in "science learning values" than the control group, meaning that the inquiry-based teaching used in this study helped the students perceive that "the values of science learning include: (a) helping students acquire problem-solving competency; (b) experiencing inquiry activities; (c) 
stimulating their own thinking; and (d) finding associations of science with things in their daily life” to increase their motivation toward science learning.

What is more, the students of the control group scored higher in "performance goal" than the experiment group, with the effect size being nearly large, meaning that the control group's motivation was stronger than the experiment group when "the goal in science learning is to compete with other students and get the teacher's attention.” The two dimensions above-learning environment stimulation and science learning values, were both intrinsic motivation. In learning, intrinsic motivation is more important than extrinsic one as the resulted interest in learning and motive power would last longer and the learning results would be better (Anderman, Noar, Zimmerman, \& Donohew, 2004). This finding showed that the inquiry-based teaching used in this study helped to increase the students' intrinsic motivation and was consistent with the WIHIC analysis results. Conversely, "performance goal" was extrinsic motivation, meaning that the science classroom environment for the control group was more likely to cause learning motivation through competitions in schoolwork.

Butler (2000) suggested that students who set up a performance goal for learning would show their characteristics of being competitive and wanting to be number one. And their focus would be placed on getting good grades. They would only work for schoolwork related to grades. This is a negative influence on learning. Moreover, in contrast to intrinsic motivation, those driven by extrinsic motivation are pursuing external stimulations or rewards (Pintrich \& Schunk, 1996). As a result, they usually prefer easy successes and do not like challenges. They tend to get direct answers instead of trying to understand the concepts behind these answers. This way, their intrinsic motivation and learning quality may be endangered.

\section{Conclusions and Implications}

This study aimed to design an inquiry-based teaching method based on conditions supporting motivation toward learning in order to increase eighth graders' motivation toward science learning. Also, it provides various evidences to show that this teaching method could achieve this purpose through cross-comparisons regarding the students' classroom environment perceptions.

This study aimed to provide the students an environment for inquiry-based learning where they were encouraged to explore and to think, could be independent, could take risks, and make mistakes. This environment provided them time and space for investigation, thinking, and discussions on what they found and how they found it. A series of activities were designed for this inquiry-based teaching, starting with an open inquiry-based question for students to make meaningful choices to develop their situational interest. This temporary interest could get the students develop themselves into the activities voluntarily. The groups' presentations showed different observations of the same thing. The resulted knowledge gaps would further arouse the students' curiosity and inspire their investigation behavior.

Through teamwork, they designed their own experiments, collected required data, analyzed those data, discussed their experiment results with their team members, organized these results, made a presentation to the class, and answered their classmates' questions. This arguing process could also help to develop the students' situational interest, so that they would learn more from their participation in the group activities to increase their collective efficacy. Lastly, they were asked to review the whole inquiry process after each inquiry for the purpose of introspection. By this way, the students could realize that they did schoolwork for learning instead of getting good grades. Moreover, the structure of asking questions was used as the scaffold for their inquiry-based learning, to build a supportive learning environment. 
According to the findings of this study, compared with the traditional textbook teaching, the inquiry-based teaching used in this study was more likely to increase the students' "learning environment stimulation," so that they could perceive this environment being supportive for inquiry-based learning. In this classroom environment, they were more likely to focus on investigation skills and processes, applied themselves to solving science problems, were more interested in participating in science learning, and placed more emphases on schoolwork. The inquiry-based teaching used in this study was more likely to facilitate the students' cooperation in learning and to make them perceive that their teacher's support was universal instead of aiming at a few students only.

Furthermore, the students perceived that the inquiry-based teaching activities, their teacher's guidance, and their interactions with their classmates were more likely to increase their motivation toward science learning. These help them to understand that he values of science learning include helping students acquire problem-solving competency, experiencing inquiry activities, stimulating their own thinking, and acquiring the ability to solve problems, which could increase their "science learning value" motivation.

These two types of motivation above were both intrinsic. In learning, intrinsic motivation is more important than extrinsic one, as intrinsic motivation keeps interest in learning, motive power, and results more consistent and positive. What is more, the traditional textbook teaching with cookbook experiments was applied to the control group. Thus, the students' motivation was more likely "performance goal," as they believed that the purpose of learning science was to compete with their classmates and get their teacher's attention. This type of motivation was extrinsic.

The research findings above provided various evidences to support the hypothesis that the inquiry-based teaching designed by this study could indeed help to increase the SMTSL and was productive. Also, the medium to large effect sizes proved the value of actually implementing this teaching method. However, there was no significant difference found in the learning motivation including "self-efficacy," "active learning strategies," and "achievement goal" between the experiment group and the control group. One possible reason is that the tests in the school were still achievement-oriented tests without including questions in relation to inquiry-based activities. As a result, the students did not have any chance to use their abilities acquired from inquiry-based learning in these tests. This issue still needs to be further studied.

\section{References}

Anderman, E. M., Eccles, J. S., Roeser, R., Wigfield, A., \& Blumenfeld, P. (2001). Learning to value mathematics and reading: relations to mastery and performance-oriented instructional practices. Contemporary Educational Psychology, 26(1), 76-95.

Anderman, E. M., Noar, S. M., Zimmerman, R. S., \& Donohew, L. (2004). The need for sensation as a prerequisite for motivation to engage in academic tasks. In P. R. Pintrich, \& M. L. Maehr (Eds.), Advances in motivation and achievement: Motivating students, improving schools: The legacy of Carol Midgley (Vol. 13, pp. 1-26). Boston: Elsevier.

Bandura, A. (1997). Self-efficacy: The exercise of control. New York, N.Y.: Freeman.

Bandura, A. (2000). Exercise of human agency through collective efficacy. Current Directions in Psychological Science, 9(3), 75-78.

Bell, R. L., Blair, L. M., Crawford, B. A., \& Lederman, N. G. (2003). Just do it? Impact of science apprenticeship program on high school students' understanding of the nature of science and scientific inquiry. Journal of Research in Science Teaching, 40(5), 487-509.

Butler, R. (2000). What learners want to know: The role of achievement goals in shaping information seeking, learning, and interest. In C. Sansone, \& J. M. Harackiewicz (Eds.), Intrinsic and extrinsic motivation: The search for optimal motivation and performance (pp. 161-194). San Diego: Academic Press. 
Chinn, C. A., \& Malhotra, B. A. (2002). Epistemologically authentic inquiry in school: A theoretical framework for evaluating in inquiry tasks. Science Education, 86(2), 175-218.

Cohen, J. (1988). Statistical power analysis for the behavioral sciences. Hillsdale, N.J.: Erlbaum.

Cohen, J. (1992). A power primer. Psychological Bulletin, 112(1), 155-159.

Fraser, B. J., McRobbie, C. J., \& Fisher, D. L. (1996, April). Development, validation and use of personal and class forms of a new classroom environment. In The Annual Meeting of the American Educational Research Association, New York, N.Y..

Hickey, D. T., \& Kindfield, A. C. H., Horwitz, P., \& Christie, M. A. T. (2003). Integrating curriculum, instruction, assessment, and evaluation in a technology-supported genetics learning environment. American Educational Research Journal, 40(2), 495-538.

Huang, T. C. I., Fraser, B. J., \& Aldridge, J. M. (1998, March). Combining quantitative and qualitative approaches in studying classroom climate in Taiwan and Australia. In The Annual Meeting of the National Association for Research in Science Teaching, San Diego, C.A..

Loewenstein, G. (1994). The psychology of curiosity: A review and reinterpretation. Psychological Bulletin, 116(1), 75-98.

Oliver, A. (2006). Creative teaching: Science in the early years and primary classroom. London: David Fulton.

Palmer, D. H. (2009). Student interest generated during an inquiry skills lesson. Journal of Research in Science Teaching, 46(2), 147-165.

Pintrich P. R. (2003). A motivational science perspective on the role of student motivation in learning and teaching contexts. Journal of Educational Psychology, 95(4), 667-686.

Pintrich, P. R., \& Schunk, D. H. (1996). Motivation in education: Theory, research and applications. Englewood Cliffs, N.J.: Prentice-Hall.

Reeve, J., Jang, H., Hardre, P., \& Omura, M. (2002). Providing a rationale in an autonomy-supportive way as a strategy to motivate others during an uninteresting activity. Motivation and Emotion, 26, 183-207.

Rennie, L. J., Goodrum, D., \& Hackling, M. (2001). Science teaching and learning in Australian schools: Results of a national study. Research in Science Education, 31(4), 455-498.

Rogoff, B., Turkanis, C. G., \& Bartlett, L. (2002). Learning together: Children and adults in a school community. New York, N.Y.: Oxford University Press.

Ryan, R. M., \& Deci, E. L. (2000). Intrinsic and extrinsic motivation: Classic definitions and new directions. Contemporary Educational Psychology, 25(1), 54-67.

Schraw, G., Flowerday, T., \& Lehman, S. (2001). Increasing situational interest in the classroom. Educational Psychology Review, 13(3), 211-224.

Schunk, D. H. (2000). Learning theories: An educational perspective (3rd ed.). Columbus, O.H.: Merrill/Prentice-Hall.

Starko, A. J. (2005). Creativity in the classroom: Schools of curious delight (3rd ed.). London: Lawrence Erlbaum Associates.

Stipek, D. J. (2002). Motivation to learn: Integrating theory and practice (4th ed.). Boston: Allyn and Bacon.

Tuan, H. L., Chin, C. C., \& Shieh, S. H. (2005). The development of a questionnaire to measure students' motivation towards science learning. International Journal of Science Education, 27(6), 639-654.

Vermetten, Y. J., Lodewijks, H. G., \& Vermunt, J. D. (2001). The role of personality traits and goal orientations in strategy use. Contemporary Educational Psychology, 26(2), 149-170.

Wang, J. R., \& Lin, S. W. (2009). Evaluating elementary and secondary school science learning environments in Taiwan. International Journal of Science Education, 31(7), 853-872.

Zimerman, B. J. (1998). Academic studying and the development of personal skill: A self-regulatory perspective. Educational Psychology, 33, 73-86.

Zimmerman, B. J. (2002). Becoming a self-regulated learner: An overview. Theory Into Practice, 41(2), 64-70.

Zimmerman, B. J. (2004). Socio-cultural influences and students' development of academic self-regulation: A social-cognitive perspective. In D. M. McInerney, \& S. van Etten (Eds.), Research on socio-cultural influences on motivation and learning: Big theories revisited (Vol. 4, pp. 139-164). Greenwich, C.T.: Information Age. 